\title{
Pendampingan Penyusunan Rencana Kerja Pembangunan Desa (RKPDesa) di Desa Setro, Kecamatan Menganti, Kabupaten Gresik
}

\author{
Erna Hendrawati \\ Universitas Wijaya Kusuma Surabaya
}

\author{
Mira Pramudianti \\ Universitas Wijaya Kusuma Surabaya
}

\author{
Khoirul Abidin \\ Universitas Wijaya Kusuma Surabaya
}

\begin{abstract}
The initial stages of village financial management are the planning, budgeting, administration, reporting, and accountability stages. Development planning for the next one year is compiled in the Village Development Work Plan (RKPDesa) document. Each village is required to prepare the RKPDesa as a form of development planning to be carried out and as the basis for the preparation of the Village Revenue and Expenditure Budget (APBDesa). Once the importance of the RKPDesa document and the activities carried out every year, it is necessary to understand and know about the preparation of the RKPDesa in accordance with government regulations for the parties involved. This article describes community service carried out by providing counseling and assistance in the preparation of the RKPDesa to village officials, the Village Representative Body (BPD), community leaders in Setro village, Menganti sub-district.
\end{abstract}

Keywords: Assistance; Planning; Village Development Work Plan

\begin{abstract}
Abstrak
Tahapan awal pengelolaan keuangan desa adalah tahap perencanaan, penganggaran, penatausahaan, pelaporan, pertanggungjawaban. Perencanaan pembangunan untuk satu tahun ke depan disusun dalam dokumen Rencana Kerja Pembangunan Desa (RKPDesa). Setiap desa wajib menyusun RKPDesa sebagai bentuk perencanaan pembangunan yang akan dilakukan dan sebagai dasar penyusunan Anggaran Pendapatan dan Belanja Desa (APBDesa). Begitu pentingnya dokumen RKPDesa dan aktivitas itu dilakukan setiap tahun, maka perlu pemahaman dan pengetahuan bagaimana tahapan penyusunan RKPDesa sesuai aturan pemerintah bagi pihak-pihak yang terlibat. Artikel ini memaparkan kegiatan pengabdian masyarakat yang dilakukan dengan memberikan penyuluhan dan pendampingan penyusunan RKPDesa kepada perangkat desa, Badan Perwakilan Desa (BPD), tokoh masyarakat di Desa Setro, Kecamatan Menganti.
\end{abstract}

Kata kunci: Pendampingan; Perencanaan; Rencana Kerja Pembangunan Desa

\section{Pendahuluan}

Desentralisasi di Indonesia mengakibatkan masyarakat harus mandiri dalam segala hal, salah satunya dalam hal perencanaan pembangunan. Proses perencanaan pembangunan desa membutuhkan pengkajian keadaaan desa yang merupakan proses penggalian dan pengumpulan data mengenai keadaan objektif masyarakat, masalah potensi dan informasi terkait yang menggambarkan secara jelas dan lengkap kondisi serta dinamika masyarakat desa. Data desa memberikan gambaran menyeluruh mengenai potensi yang meliputi sumber daya alam, sumber daya manusia, sumber dana, kelembagaan, sarana dan prasarana fisik dan sosial kearifan lokal, ilmu pengetahuan dan teknologi serta permasalahan yang dihadapi desa.

Rencana pembangunan desa disusun untuk menjamin keterkaitan dan konsistensi antara perencanaan, penganggaran, pelaksanaan dan pengawasan [1]. Perencanaan adalah suatu proses mempersiapkan secara sistematis kegiatan-kegiatan yang akan dilakukan untuk mencapai suatu tujuan tertentu. Perencanaan pembangunan adalah suatu proses perumusan alternatif atau 
keputusan-keputusan yang didasarkan pada fakta-fakta yang akan digunakan sebagai bahan untuk melaksanakan suatu rangkaian kegiatan/aktivitas kemasyarakatan, baik yang bersifat fisik (material) maupun nonfisik (mental dan spiritual), dalam rangka mencapai tujuan yang lebih baik [2].

Desa menurut UU No. 6 tahun 2014 adalah kesatuan masyarakat hukum yang memiliki batas wilayah yang berwenang untuk mengatur dan mengurus urusan pemerintahan, kepentingan masyarakat setempat berdasarkan prakarsa masyarakat, hak asal usul, dan atau hak tradisional yang diakui dan dihormati dalam system pemerintahan Negara Kesatuan Republik Indonesia. Untuk mendapatkan dukungan dan partisipasi yang kuat dari masyarakat terhadap pembangunan desa, maka masyarakat harus dilibatkan dalam proses pengambilan keputusan termasuk pada tahapan perencanaan pembangunan desa. Dengan demikian diharapkan akan timbul suatu rasa tanggung jawab bersama seluruh masyarakat desa terhadap pembangunan di desanya. Namun, untuk bisa berpartisipasi dalam pembangunan, menurut [3] masyarakat perlu memiliki pemahaman yang luas tentang pembangunan partisipatif, khususnya dalam aspek perencanaan. Pemahaman masyarakat terhadap partisipasi dalam perencanaan sangat diperlukan dalam pembangunan partisipatif karena pemahaman terhadap perencanaan dalam pembangunan partisipatif akan menimbulkan suatu kesadaran masyarakat betapa pentingnya partisipasi masyarakatPerencanaan adalah suatu proses mempersiapkan secara sistematis kegiatankegiatan yang akan dilakukan untuk mencapai suatu tujuan tertentu.

Perencanaan pembangunan desa merupakan proses pengambilan keputusan yang dilakukan secara terpadu bagi peningkatan kesejahteraaan masyarakat desa dengan memanfaatkan dan mempertimbangkan kemampuan sumber daya yang dimiliki desa. Pengelolaan keuangan desa di mulai dari tahapan perencanaan, penganggaran, penatausahaan, pelaporan dan pertanggungjawaban. Tahapan perencanaan terkait dengan rencana pembangunan desa yang dapat terlihat dalam Rencana Pembangunan Jangka Menengah Desa (RPJMDesa) yang disusun setiap enam tahun dan Rencana Kerja Pembangunan Desa (RKPDesa). RKPDesa adalah penjabaran dri RPJMDesa yang memuat rancangan kerangka ekonomi desa dengan mempertimbangkan pagu indikatif yang akan diterima desa, program prioritas pembangunan desa yang direncanakan desa maupun program dari pemerintah kabupaten dan propinsi. RKPDesa berisi rencana pembangunan satu tahun kedepan.

Permendagri No. 114 tahun 2014 pasal 30 ayat 2 tentang pedoman pembangunan desa secara eksplisit menyatakan: penyusunan RKPDesa sebagaimana yang dimaksud pada pasal (1) dilakukan dengan kegiatan yang meliputi: penyusunan perencanaan pembangunan desa melalui musyawarah desa, pembentukan tim penyusun RKPDesa, pencermatan ulang dokumen RPJMDesa, penyusunan rancangan RKPDesa, penyusunan RKPDesa melalui musyawarah perencanaan pembangunan desa, penetapan RKPDesa, perubahan RKPDesa, pengajuan daftar usulan RKPDesa.

Menelaah dari regulasi tersebut, tahap awal penyusunan RKP Desa adalah penyusunan perencanaan pembangunan desa melalui musyawarah desa yang diselenggarakan oleh BPD sebagaimana diatur dalam permendagri No. 114 Tahun 2014 pasal 31 ayat (1) tentang pedoman pembangunan desa yang mengatur bahwa BPD menyelenggarakan musyawarah desa menjadi dasar atau pedoman pemerintah desa dalam menyusun rancangan RKPDesa dan daftar usulan RKPDesa. Pentingnya dokumen RKPDesa sebagai tahapan awal dalam pengelolaan keuangan desa dan sebagai dasar penyusunan Anggaran Pendapatan dan Belajan Desa (APBDesa), maka pengabdian ini bertujuan untuk melakukan pendampingan kepada perangkat desa Setro kecamatan Menganti Gresik dalam melakukan penyusunan dokumen RKPDesa. Tujuan dari pengabdian ini adalah agar pelaksanaan penyusunan RKPDesa sesuai dengan aturan Pemerintah, memberikan tambahan informasi dan melakukan focus group discussion (FGD) terkait kendala pelaksanaan penyusunan RKPDesa. 


\section{Metode Pelaksanaan}

Metode yang digunakan dalam pengabdian ini berupa penyuluhan dan pendampingan para peserta yang terdiri perangkat pemerintah desa, Badan Permusyawaratan Desa (BPD) beserta tokoh masyarakat desa Setro. Tahap awal kegiatan adalah melakukan survei desa dan audensi persiapan pelaksanaan pelatihan dengan menjaring aspirasi dari kepala desa, sekretaris desa, ketua BPD, tokoh masyarakat yang memiliki pengaruh di desa Setro. Hasil audiensi untuk mendapatkan informasi dan pemetaaan masalah desa kemudian menentukan metode serta waktu yang tepat untuk pelatihan.

Tahap kedua adalah memberika penyuluhan materi RKP Desa dengan teknik brainstorming (curah pendapat) yaitu teknik kreativitas yang mengupayakan pencarian penyelesaian suatu masalah dengan mengumpulkan gagasan dari peserta. Penyajian materi diikuti dengan diskusi, tanya jawab dan mengakomodasi semua saran dan masukkan dari peserta. Selanjutnya akan dilakukan pendampingan penyusunan RKPDesa dengan pendekatan partisipatif dan berdasarkan kondisi riil desa Setro.

Di akhir kegiatan, dilakukan evaluasi hasil pelatihan penyusunan RKP Desa. Para peserta diberikan kuesioner untuk diisi, dengan tujuan mengetahui sejauh mana pemahaman peserta terhadap materi dan keseluruhan proses pelatihan. Keseluruhan alur kegiatan pelatihan dapat dilihat pada Gambar 1.

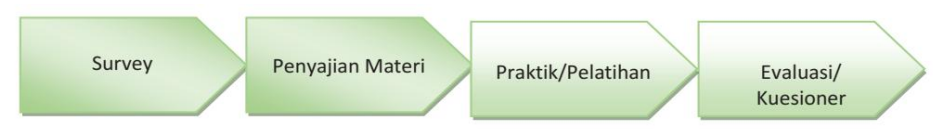

Gambar 1. Alur Kegiatan Pengabdian Masyarakat

\section{Hasil dan Pembahasan}

Beberapa kegiatan yang dilakukan adalah pendampingan penyusunan RKPDesa di Desa Detro. Pendampingan penyusunan RKPDesa dilakukan sebelum dan sesudah penyuluhan tanggal 23 Juni 2021. Pendampingan sebelum penyuluhan dilakukan dengan perangkat desa dan perwakilan BPD (Gambar 1). Pada kegiatan ini dilakukan dengan Focus Grup Discussion dengan peserta tentang pelaksanaan tahapan penyusunan RKPDesa dan kendala yang dihadapai dalam penyusunan RKPDesa. Adanya FGD diharapkan dapat menambah informasi dan profesionalisme perangkat desa dalam melakukan tugasnya. Karena profesionalisme perangkat desa dapat memperlancar proses penyusunan dokumen dalam pengelolaan keuangan desa [4]. Desa setro sudah melakukan tahapan sesuai Permendagri No.114 tahun 2014 dengan melakukan musyawarah desa untuk menyampaikan capaian pelaksanaan pembangunan satu tahun sebelumnya dan mencermati ulang dokumen RPJMDesa Setro dan pembentukan tim penyusun RKPDesa. Selanjutnya tim penyusun akan mencermati dana yang akan diterima desa (pagu indikatif) dan menyelaraskan program atau kegiatan yanga masuk desa, kendala yang dialami adanya keterlambatan penyampaian pagu indikatif sehingga tahapan itu agak mundur pelaksanaannya. Setelah pagu indikatif diterima maka tim penyusun RKPDesa menyusun rancaaan RKPDesa dengan berpedaman hasil kesepakatan musyawarah desa (musdes), pendapatan asli desa, hasil pencermatan ulang dokumen RPJMDesa. Rancangaan RKPDesa berisi evaluasi pelaksanaan RPDesa tahun sebelumnya, prioritas program, kegiatan dan anggaran desa yang dikelola oleh desa, prioritas program yang dikelola melalui kerja sama antar desa dan pelaksanaan kegiatan desa. Tahapan selanjutnya adalah mengadakan musyawarah perencanaan pembangunan desa (Musrebangdes) untuk membahas rancangan RKPDesa. Hasil musyawarah itu dituangkan dalam dokumen RKPDesa dan selanjutnya RKPDesa itu ditetapkan dengan peraturan desa. Kendala yang dihadapi pemerintah desa terkait RKPDesa tahun 2020, walaupun RKPDesa 
sudah ditetapkan dengan peraturan pemerintah desa tetapi berkali-kali mengalami perubahan karena adanya kebijakan dari pemerintah pusat yang memutuskan agar dana yang diterima setiap desa digunakan untuk pencegahan, penanggulaang pandemic covid-19 dan memberi bantuan terhadap warga masyarakat yang terkena dampak pandemi covid-19. Akibatnya beberapa kali RKPKdesa mengalami perubahan sesuai dengan kebijakan pemerintah, program pembangunan desa yang sudah di rancangkan dalam RKPDesa tidak bisa dilakukan karena pengalihan program penggunaan dana yang diterima desa.
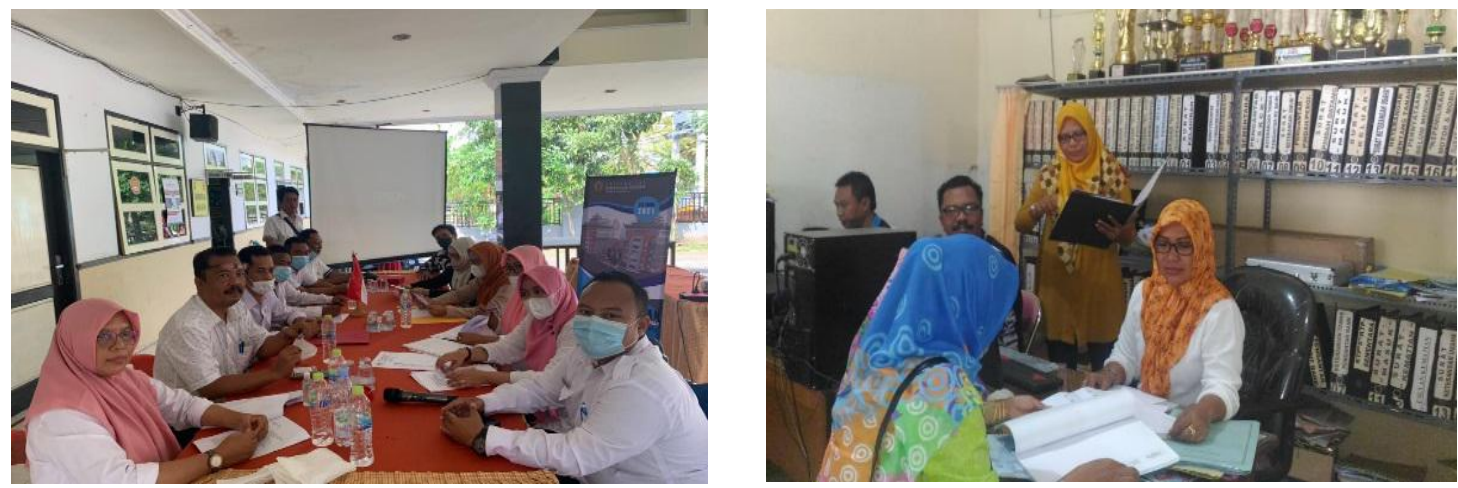

Gambar 1. Kegiatan Pendampingan Sebelum Penyuluhan Dilakukan

Setelah tahapan penyuluhan, tim pengabdian masyarakat melanjutkan pendampingan terkait dokumen RKPDesa yang telah disusun. Pendampingan dilakukan untuk mengevaluasi dokumen RKPDesa Setro baik dari kegiatan yang direncanakan dan keterkaitan dengan penyusunan anggran dengan membuat dokumen Anggaran Pendapatan dan Belanja Desa (APBDesa). Hal itu ditunjukkkan pada Gambar 2.

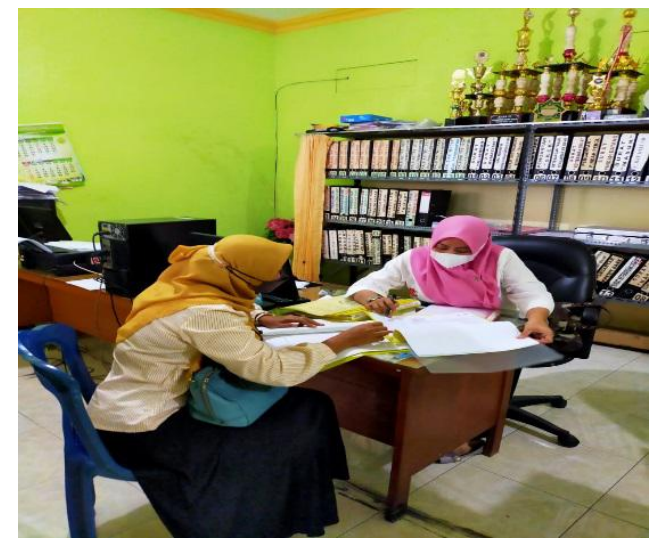

Gambar 2. Kegiatan Pendampingan Setelah Penyuluhan

Selain pendampingan, pengabdian masyarakat ini juga melakukan penyuluhan kepada perangkat desa setro, perwakilan BPD, tokoh masyarakat dan perwakilan Lembaga desa seperti Ketua PKK dan paguyunan. Gambar 3 menunjukkan saat kehadiran peserta penyuluhan. Penyuluhan dilakukan dengan menyampaikan materi tentang tahapan dalam penyusunan RKPDesa. Kegiatan ini diharapkan dapat menambah informasi dan wawasan peserta bagaimana cara penyusunan RKPDesa sesuai dengan aturan pemerintah. 

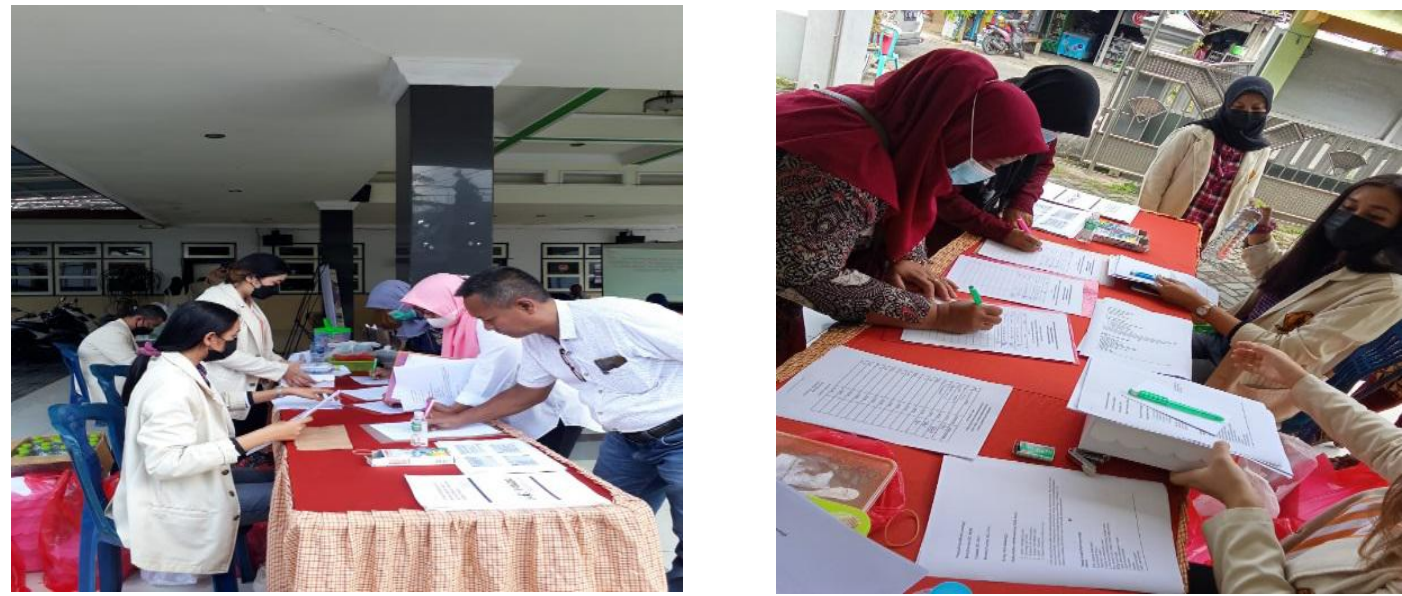

Gambar 3. Kehadiran Peserta

Sebelum pemaparan materi penyuluhan, Kepala Desa memberikan sambutan dan ucapan terima kasih kepada tim pengabdian atas penyuluhan dan pendampingan terkait penyusunan RKPDesa. Selanjutnya, pemaparan materi dan peserta antusias menyimak dan mencermati hardcopy materi, terlihat pada Gambar 4.
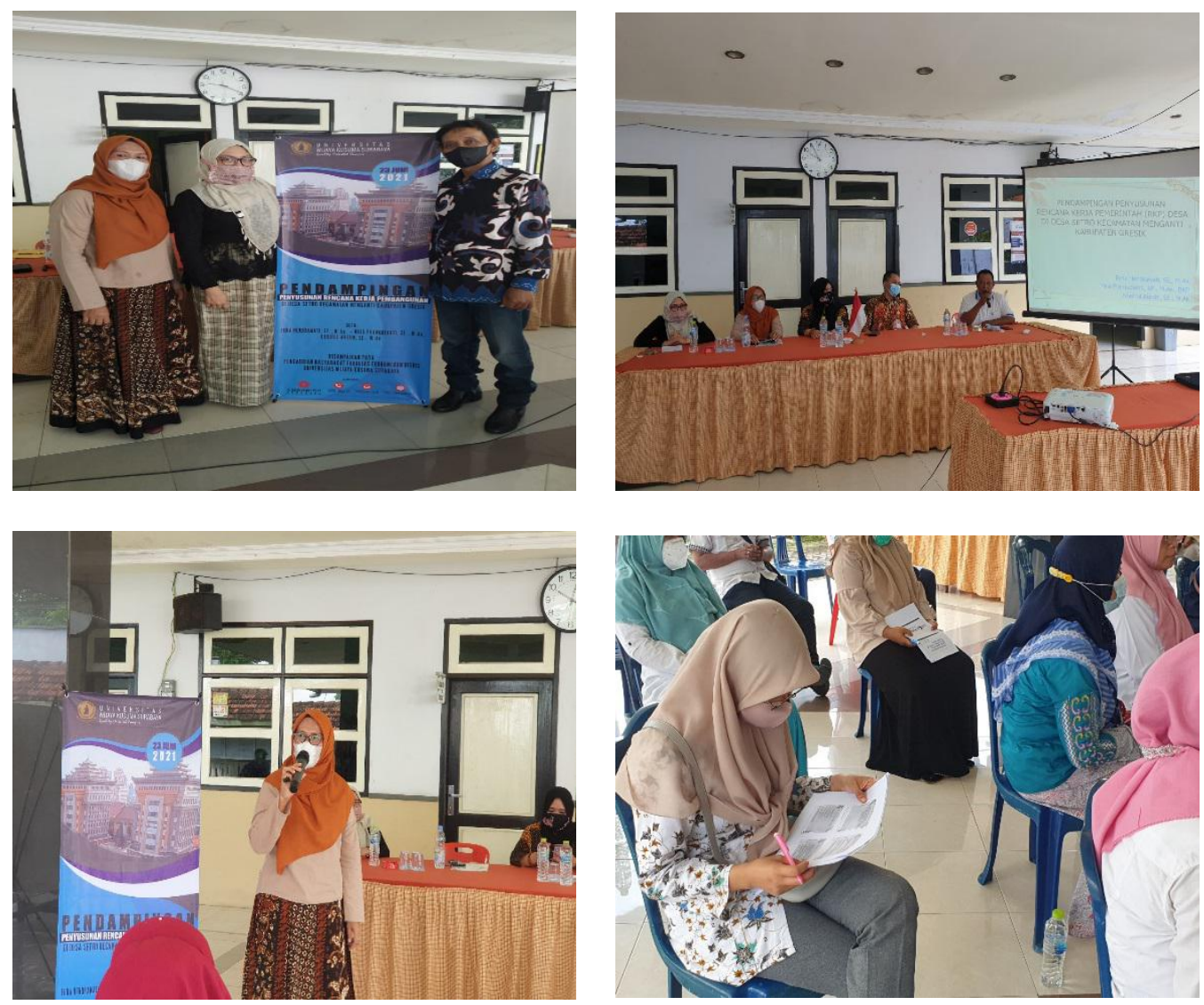

Gambar 4. Kegiatan Penyuluhan 
Evaluasi setelah pemaparan materi dilakukan dengan tanya jawab untuk saling berbagi pengalaman, kendala dan penyelesaian yang mereka hadapi di lapangan. Setelah tanya jawab sebagai bentuk evaluasi terhadap materi yang dipaparkan, kami melalukan permainan dan olah raga kecil agar peserta bisa senang dan rileks. Aktivitas ini dapat dilihat pada Gambar 5.
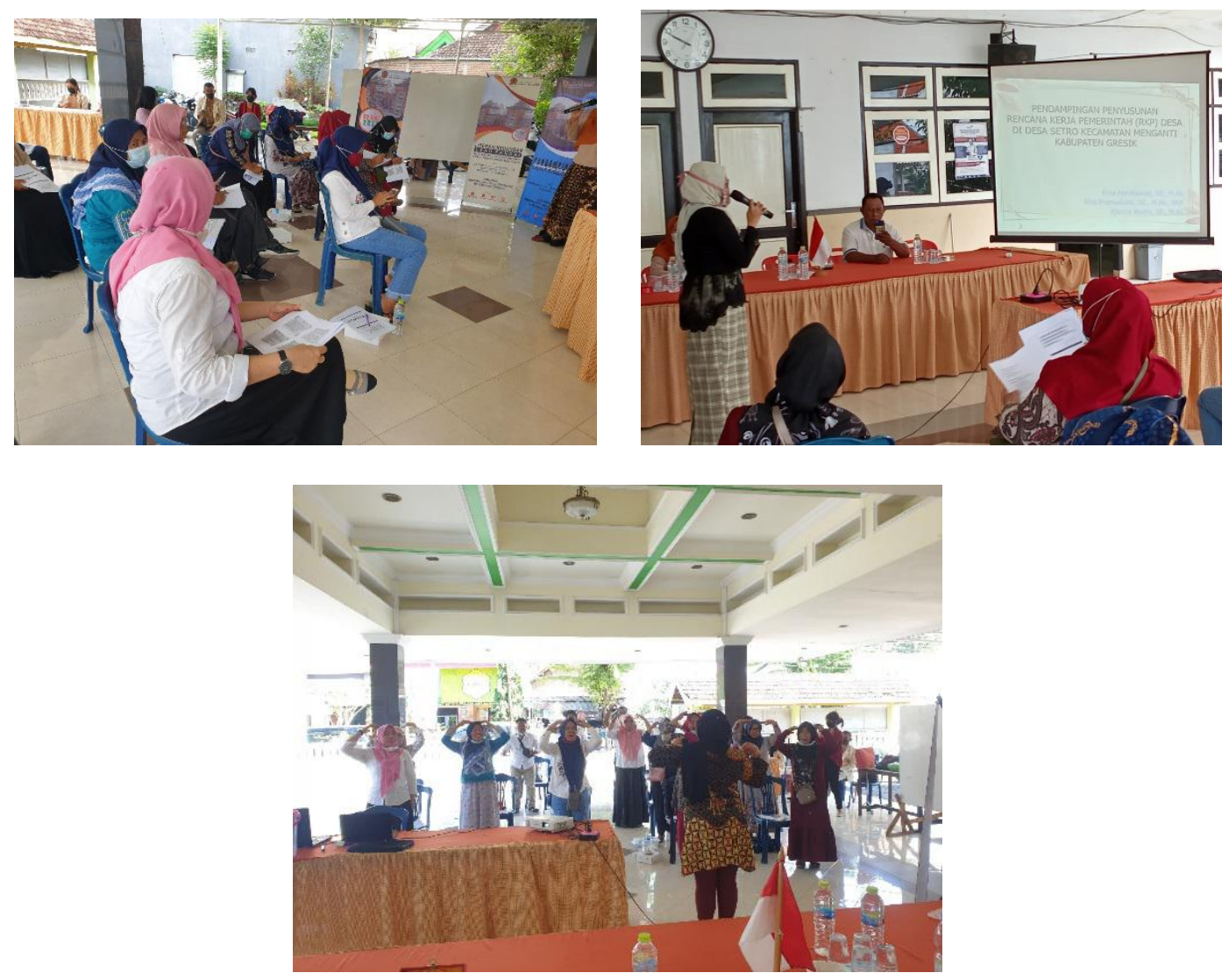

Gambar 5. Kegiatan Tanya Jawab

Di akhir kegiatan penyuluhan, tim pengabdian masyarakat memberikan tali asih kepada desa dan foto bersama sebagai bentuk ucapan terima kasih, terlihat pada Gambar 6.

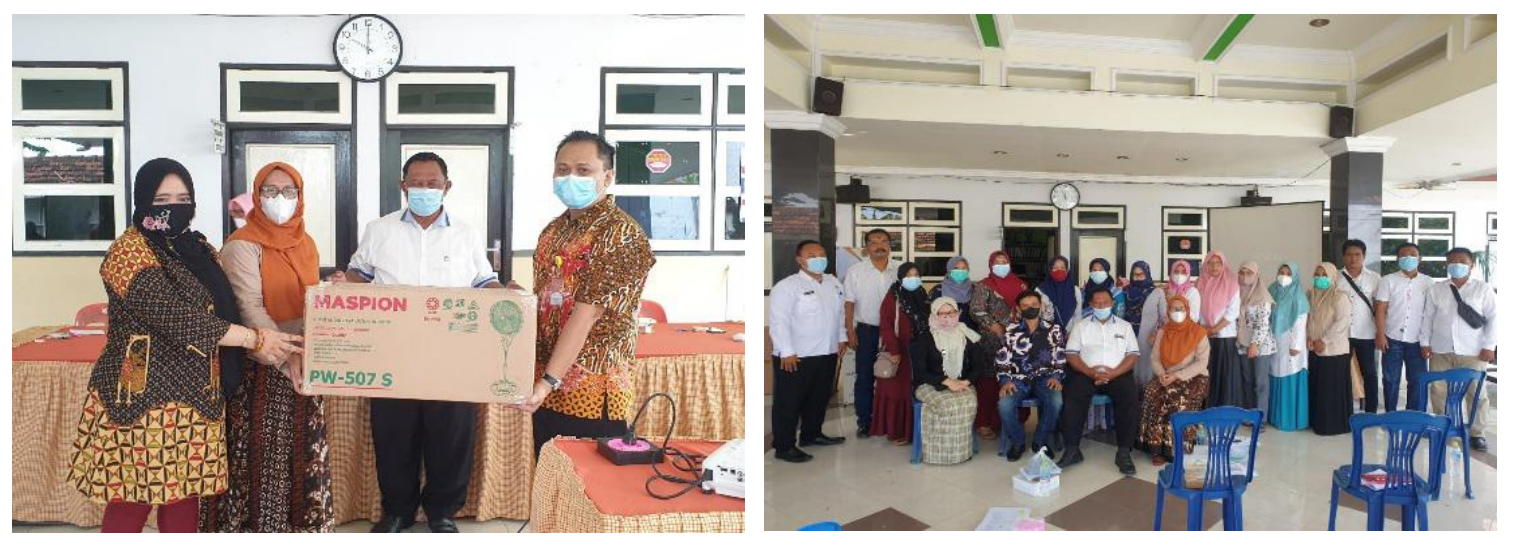

Gambar 6. Pemberian Tali Asih dan Foto Bersama Peserta 


\section{Kesimpulan}

Penyelenggaraan kegiatan pengabdian masyarakat pendampingan penyusunan Rencana Kerja Pembanguunan Desa (RKP Desa) di Desa Setro, Kecamatan Menganti, Kabupaten Gresik dapat terlaksanakan dengan baik melalui kegiatan penyuluhan dan pendampingan sesuai tujuan. Pendampingan dilakukan dengan focus grup discussion bersama perangkat desa Setro yang memberikan kontribusi evaluasi dokumen RKP Desa Setro serta mencari penyelesaian permasalahan dan kendala yang terjadi saat penyusunan RKP Desa. Hasil focus grup discussion memberikan masukan materi apa yang akan disampaikan saat penyuluhan terkait RKP Desa agar materi yang disampaikan sesuai dengan informasi yang dibutuhkan. Kegiatan ini mendapat sambutan baik dari seluruh perangkat desa dan memberikan tambahan informasi dan wawasan dalam penyusunan tahapan perencanaan pengelolaan keuangan desa karena pentingnya dokumen RKPDesa yang harus disusun setiap tahun dan sebagai dasar penyusunan anggaran dan dasar pelaksanaan kegiatan dan penggunaan dana.

\section{Ucapan Terima Kasih}

Terima kasih seluruh perangkat Desa Setro, Lembaga Penelitian dan Pengabdian Masyarakat (LPPM), Universitas Wijaya Kusuma Surabaya dalam membantu terselenggarannya kegiatan pendampingan peyusunan RKPDesa. Terima kasih juga kepada tim pengabdian dan Fakultas Ekonomi dan Bisnis, Universitas Wijaya Kusuma Surabaya.

\section{Daftar Pustaka}

[1] E. Hendrawati and M. Pramudianti, "Partisipasi, Transparansi Dan Akuntabilitas Perencanaan Dan Penganggaran Dana Desa,” J. Ris. Akunt. Kontemporer, vol. 12, no. 2, pp. 100-108, 2020, doi: 10.23969/jrak.v12i2.3113.

[2] T. F. D. P. AL Riyanto, "eJournal Administrasi Negara, 2015, 3 (1) 119-130 ISSN 2337-7542 , ejournal.ip.fisip-unmul.ac.id | AKUNTABILITAS FINANSIAL DALAM PENGELOLAAN ALOKASI DANA DESA (ADD)," Statew. Agric. Land Use Baseline 2015, vol. 1, no. 1, pp. 119130, 2015, doi: 10.1017/CBO9781107415324.004.

[3] S. Susetiawan, D. Mulyono, and M. Y. Roniardian, "Penguatan Peran Warga Masyarakat Dalam Perencanaan, Penganggaran, dan Evaluasi Hasil Pembangunan Desa," J. Pengabdi. Kpd. Masy., vol. 4, no. 1, p. 109, 2018, doi: 10.22146/jpkm.27512.

[4] E. Hendrawati, "Asset Utilization Optimization, Local Government Support, Asset Management Professionalism Towards Increasing Village Original Income," J. Akunt., vol. 11, no. 2, pp. 163-174, 2021, doi: 10.33369/j.akuntansi.11.2.163-174. 


\section{Afiliasi:}

Erna Hendrawati*, Mira Pramudianti, Khoirul Abidin

Universitas Wijaya Kusuma Surabaya

Jalan Dukuh Kupang XXV/54 Surabaya

Email: hendrawati@uwks.ac.id*,mirapramudianti@yahoo.com,khoirulabidin@uwks.ac.id 